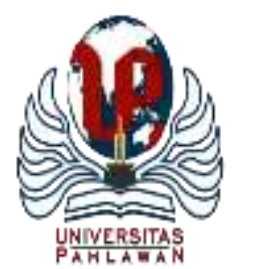

Edukatif : Jurnal Ilmu Pendidikan Volume 4 Nomor 1 Tahun 2022 Halm 565 - 571

EDUKATIF: JURNAL ILMU PENDIDIKAN

Research \& Learning in Education

https:/ledukatif.org/index.php/edukatif/index

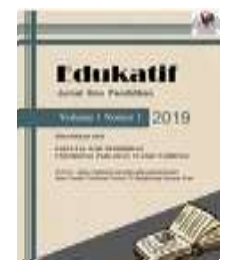

\title{
Peran Kepala Sekolah dalam Meningkatkan Kinerja Tenaga Guru Sekolah Dasar dan Sekolah Menegah Pertama
}

\author{
Nuriati $^{1 凶}$, Muhammad Azis ${ }^{2}$, Husain $\mathrm{AS}^{3}$ \\ SD Negeri Lakkang Makassar, Indonesia ${ }^{1}$ \\ STKIP Pembangunan, Indonesia ${ }^{2,3}$ \\ E-mail : nuriati.arapang@gmail.com ${ }^{1}, \underline{\text { azis_feunm@yahoo.com }}^{2}$, $\underline{\text { husainaspale@gmail.com }}^{3}$
}

\begin{abstract}
Abstrak
Guru dengan tingkat kompetensi yang tinggi dituntut untuk mencapai tujuan pendidikan. Penelitian bertujuan mendeskripsikan peran kepala sekolah dan kendala kepala sekolah dalam meningkatkan kinerja tanaga guru SDN Lakkang dan SMPN 44 Makassar. Teknik pengumpulan data melalui observasi wawancara dan kuesioner. Teknik analisis data mengunakan analisis deskriptif kualitatif meliputi pengumpulan data reduksi data dan pengajian data. Hasil penelitian menujukan 1) Peran kepala sekolah di SDN Lakkang dan SMPN 44 Kota Makassar dalam meningkatkan kinerja tenaga pengajar yakni sebagai manajerial, supervisor dan motivator namun belum dilaksanakan dengan baik. 2) Kendala yang dihadapi kepala sekolah dalam menjalankan perannya yakni masih terdapat tenaga pengajar yang tidak melaksanakan tugas yang diberikan dengan baik, sulitnya memenuhi waktu yang tepat atau menyesuaikan waktu antar kepala sekolah dan staf pengajar. Disimpulkan bahwa peran kepala sekolah sangat penting dalam meningkatkan kinerja tenaga pengajar tapi terdapat beberapa kendala yang dihadapi namun ada upayah yang dilakukan agar peningkatan kinerja tenaga pengajar dicapai.
\end{abstract}

Kata Kunci: Kualitas Kepala Sekolah, Pemecah Masalah, Kinerja Tenaga Guru

\begin{abstract}
Teachers with a high level of competence are required to achieve educational goals. This study aims to describe the principal's role and the principal's obstacles in improving the performance of teachers at SDN Lakkang and SMPN 44 Makassar. Data collection technique was through interview observations and questionnaires. The data analysis technique used descriptive qualitative analysis including data collection, data reduction, and data study. The results of the study show 1) The role of the principal at SDN Lakkang and SMPN 44 Makassar City in improving the performance of the teaching staff, namely as managerial, supervisor, and motivator, but has not been implemented properly. 2) Obstacles faced by principals in carrying out their roles are that there are still teaching staff who do not carry out their assigned tasks properly, it is difficult to meet the right time or adjust the time between the principal and teaching staff. It was concluded that the role of the principal is very important in improving the performance of the teaching staff but there are several obstacles faced but there are efforts made to improve the performance of the teaching staff.
\end{abstract}

Keywords: Quality Principals, Problem Solvers, Teacher Performance

Copyright (c) 2022 Nuriati, Muhammad Azis, Husain AS

$\triangle$ Corresponding author:

Email : nuriati.arapang@gmail.com

DOI : https://doi.org/10.31004/edukatif.v4i1.1835

ISSN 2656-8063 (Media Cetak)

ISSN 2656-8071 (Media Online)

Edukatif : Jurnal Ilmu Pendidikan Vol 4 No 1 Tahun 2022

p-ISSN 2656-8063 e-ISSN 2656-8071 


\section{PENDAHULUAN}

Kepala sekolah merupakan unsur yang sangat penting dalam dunia pendidikan. Untuk mencapai pendidikan yang berkualitas, guru yang berkualitas dituntut untuk mendidik siswanya (Ayok, 2021). Salah satu strategi yang paling efektif dan efisien untuk meningkatkan kinerja guru adalah dengan menyediakan sarana dan prasarana yang memadai (Mihmidaty Ya'cub, 2021). Kepala sekolah, serta guru dan siswa, harus bekerja sama untuk memastikan bahwa guru yang berkualitas dapat bekerja dengan baik (Ramdani, 2018).

Kepala sekolah sebagai sosok profesional dalam organisasi sekolah yang bertugas mengelola seluruh elemen organisasi di lingkungan sekolah memiliki banyak tugas dan tanggung jawab dalam hal peningkatan kinerja guru (Muflihah, 2019). Dalam hal ini, kepala sekolah harus memiliki keterampilan pribadi, sosial, teknis, dan manajerial untuk mencapai tujuan sekolah (Tri Yuliani, 2016).

Upaya kepala sekolah dalam membina guru, memberikan pelatihan, dan menyempurnakan strategi untuk meningkatkan kinerja guru yang berkualitas belum baik, dan upaya kepala sekolah dalam menjelaskan tugas dan tanggung jawabnya sebagai kepemimpinan dianggap belum terlaksanakan dengan baik (Ayenita Roringi1, 2021). Karena kepemimpinan belum sepenuhnya bertanggung jawab sebagai motor penggerak utama bagi perkembangan dan kemajuan sekolah, dalam hal ini peningkatan kinerja guru, maka keberhasilan organisasi sekolah sangat bergantung pada kepemimpinan (Yeni Wulandari, Eva Dwi Sartika, 2018).

Rendahnya peran kepala sekolah disebabkan karena kegiatan supervisi akademik kepala sekolah yang kurang baik. Guru akan mendapat bantuan atau jasa profesional dari supervisi akademik yang baik agar kinerjanya dapat maksimal, dan guru tidak mudah bosan atau putus asa dalam upayanya meningkatkan kinerjanya (Prasetia, 2021). Lebih lanjut, kepala sekolah terus berkinerja buruk dalam perannya sebagai supervisor, manajer, dan motivator, mengarahkan guru untuk menciptakan lingkungan belajar yang aktif, kreatif, dan menyenangkan untuk meningkatkan kinerja guru (Yantoro, 2020).

Peran kepala sekolah yang baik dan terarah akan meningkatkan kinerja guru, oleh karena itu seorang kepala sekolah harus memberikan contoh bagaimana meningkatkan kinerja guru (Muqowim, 2021). Karena kinerja guru yang baik tergantung pada peran kepala sekolah yang baik, maka peran kepala sekolah harus dilaksanakan dengan sebaik-baiknya (Sultoni \& Nurabadi, 2019). Untuk meningkatkan kinerja guru, kepala sekolah harus memberikan pengembangan profesional kepada guru, mengunjungi kelas, mengadakan pertemuan rutin, dan memberikan pelatihan kepada guru (Harun \& Nurlisa, 2021).

Keterbatasan penelitian terkait peran kepala sekolah dalam meningkatkan kinerja tenaga guru. Penelitian (Aprilianti, 2019) meningkatkan kualitas guru dengan mengulas karya sastra literatur dan literasi setiap apel pagi. Kepala sekolah dalam penelitian ini telah memberikan strategi yang baik untuk meningkatkan kualitas guru, namun masih terdapat guru yang kurang mumpu dalam menjalankan tugas dan tanggung jawabnya. Sedangkan penelitian (Aqib, 2015) peningkatan kinerja guru melalui supervise edukatif kolaboratif secara periodik. Kepala sekolah telah memberikan pelayanan prima kepada guru dalam penelitian ini, seperti menekankan pentingnya perencanaan pembelajaran, hal tersebut masih belum tercapai sesuai dengan tujuan yang diharapkan untuk meningkatkan kinerja guru yang berkualitas. Studi sebelumnya telah mendorong peneliti untuk melakukan penelitian lebih lanjut tentang peran kepala sekolah dalam meningkatkan kinerja guru; namun, penelitian ini akan fokus pada bagaimana peran kepala sekolah dimainkan, dengan tujuan untuk menentukan bagaimana meningkatkan kinerja guru.

Penelitian ini penting dalam dunia pendidikan karena membantu untuk mencapai tujuan pendidikan. Ketika masalah muncul sebagai akibat dari kinerja guru, kepemimpinan profesional diperlukan untuk memecahkan masalah ini. SDN Lakkang dan SMPN 44 Makassar sama-sama mengalami masalah serupa. Menurut penelitian, sekolah menghadapi sejumlah tantangan dalam meningkatkan kinerja guru, tetapi kepala sekolah dan guru bekerja untuk meningkatkan kinerja mereka. Peneliti tertarik untuk mempelajari lebih lanjut tentang permasalahan yang dihadapi kepala sekolah sebagai akibat dari penjelasan tersebut. Oleh karena itu, 
567 Peran Kepala Sekolah dalam Meningkatkan Kinerja Tenaga Guru Sekolah Dasar dan Sekolah Menegah Pertama - Nuriati, Muhammad Azis, Husain AS

DOI: https://doi.org/10.31004/edukatif.v4i1.1835

penelitian ini berfokus pada peran kepala sekolah dalam meningkatkan kinerja guru di SDN Lakkang dan SMPN 44 Makassar.

\section{METODE PENELITIAN}

Penelitian ini dilaksanakan di SDN Lakkang dan SMPN 44 Makassar, Kec. Tallo, Kota. Makassar pada bulan April hingga Juni 2021. Jenis penelitian merupakan penelitian deskriptif kualitatif, yang menggambarkan atau menjelaskan fenomena sedalam mungkin melalui pengumpulan data secara alami, holistik, dan spesifik. Subjek penelitian yakni kepala sekolah SDN Lakkang dan SMPN 44 Kota Makassar, guru SDN Lakkang berjumlah 22 orang dan guru SMPN 44 Kota Makassar berjumlah 10 orang. Dengan demikian subjek penelitian yang akan menjadi sasaran atau objek penelitian sebanyak 24 orang. Desain penelitian mendeskripsikan peran kepala sekolah, sebagai menejerial, supervisor, motivator. Uji keabsaahan data mengunakan statistik deskriptif beberapa persentase dalam rangka peningkatan kualitas pengajaran (guru), data yang diperoleh dengan observasi, wawancara dan kuesioner digunakan untuk menarik kesimpulan lebih lanjut dari statistik varians persentase. Teknik pengumpulan data melalui observasi, wawancara dan kuesioner. Teknik analisis data menggunakan analisis deskriptif kualitatif, meliputi pengumpulan data, reduksi data, dan pengajian data

Dalam tahap pengumpulan data observasi dilakukan (pengamatan) untuk memantau secara langsung kegiatan yang dilakukan guru untuk meningkatkan kualitas guru dan untuk meningkatkan hasil belajar siswa, wawancara dan kuesioner dilakukan dengan mengajukan pertanyaan-pertanyaan dan memberikan butir-butir soal sesuai tujuan dan rumasan masalah, berikut:

1. Bagimanakah peran kepala sekolah sebagai menejerial, supervisor, dan motivator dalam meningatkan kinerja tanaga guru SDN Lakkang dan SMPN 44 Makassar.

2. Kendala-kendala apa sajakah yang dihadapi kepala sekolah dalam meningkatkan kinerja tanaga guru SDN Lakkang dan SMPN 44 Makassar.

\section{HASIL DAN PEMBAHASAN PENELITIAN}

Proses penelitian ini dilakukan dengan melakukan wawancara kepada narasumber.

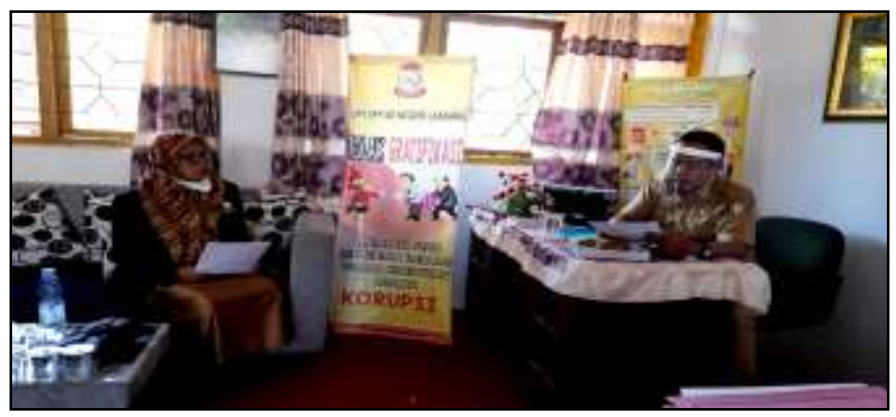

Gambar 1. Wawancara dengan salah satu narasumber

Peran kepala sekolah sebagai menejerial, supervisor, dan motivator dalam meningatkan kinerja tanaga guru SDN Lakkang dan SMPN 44 Makassar dapat dilihat tabel berikut:

\section{Tabel 1}

Peran kepala sekolah sebagai menejerial dalam meningkatkan kinerja tenaga guru

\begin{tabular}{cl}
\hline Idensial & \multicolumn{1}{c}{ Hasil } \\
\hline K.P & $\begin{array}{l}\text { Menyatakan bahwa: berperan aktif sabagai menejerial dalam perumusan misi dan misi, dan } \\
\text { melaksanakan program sekolah jangka pendek, menengah dan panjang untuk meningkatkan } \\
\text { kualitas kegiatan guru. Upayah lainnya utuk meningkatkan kualitas pengelolaan staf pengajar, } \\
\text { dengan melibatkan seluruh guru dalam pembentukan supervisi. }\end{array}$ \\
\hline K.P & Juga menyatakan bahwa: untuk mewujudkan sumber daya manusia(SDM) tenaga pengajar yang \\
\hline
\end{tabular}


handal, dilakukan dengan pengawasan dan peningkatan pelatihan tenaga pengajar. Oleh karna pelaksanaan supervisi sesuai dengan kebutuhan pengembangan professional tenaga pengajar, serta mengatur dengan baik pelaksanaan pelatihan disekolah maupun diluar sekolah sebagai upayah peningkatan kualitas tenaga pengajar agar menjadi professional.

\begin{tabular}{cl} 
Tabel 2 \\
Peran kepala sekolah sebagai supervisior dalam meningkatkan kinerja tenaga guru \\
\hline Idensial
\end{tabular}

\section{Tabel 4}

\begin{tabular}{cl}
\multicolumn{3}{c}{ Respon guru terhadap peran kepala sekolah dalam meningkatkan kinerja tenaga guru } \\
\hline Idensial & \multicolumn{1}{c}{ Hasil } \\
\hline AS & $\begin{array}{l}\text { Menyatakan bahwa: upayah yang dilakukan kepal sekolah untuk meningkatkan tenaga pengajar } \\
\text { adalah promosi atau partisipasi guru dalam kegiatan MGMP/KKG, workshop, pelatihan dan } \\
\text { kegiatan lainnya agar menjadi profesional. }\end{array}$ \\
\hline AN & $\begin{array}{l}\text { Juga menyatakan bahwa: kedua Kepala Sekolah telah melakukan dengan baik dalam hal } \\
\text { pemberdayaan kinerja guru, pemantauan administrasi dan supervisi klinis dan pembinaan tindak } \\
\text { lanjut. }\end{array}$ \\
\hline HJ & $\begin{array}{l}\text { Menyatakan bahwa: kepala sekolah dalam menjalankan perannya untuk melakukan supervisi } \\
\text { administrasi, supervisi akademik, dan supervisi klinis, sudah dilakaukan dengan baik. }\end{array}$ \\
\hline HZ & $\begin{array}{l}\text { Juga menyatakan bahwa: kepala sekolah telah menjalankan visi dan misi sekolah dalam } \\
\text { mengelola sekolah, memimpin sekolah, dan membina tenaga pengajar melalui monitoring dan } \\
\text { evaluasi. }\end{array}$ \\
\hline
\end{tabular}

HM Menyatakan bahwa: kepala sekolah dalam mengelola sekolah, memimpin sekolah, membina tenaga pengajar, memantau pelaksanaan pembelajaran dan kinerja tenaga pengajar, pengambilan keputusan, dan pemberdayaan tenaga pengajar telah menjadikan visi dan misi sebagai pedomannya di dalam menjalankan peran kepala sekolah sebagai manajerial, supervisor, dan motivator.

IY Juga menyatakan bahwa: dalam pengambilan keputusan, kepala sekolah sudah sering menerapkan gaya kepemimpinannya, termasuk dalam memberdayakan tenaga pengajar. Tetapi kepala sekolah kadangkadang melakukan supervisi administrasi, supervisi akademik, dan supervisi klinis.

JK Menyatakan bahwa: kepala sekolah telah melakukan supervisi, baik supervisi administrasi, supervisi akademik, maupun supervisi klinis dengan sangat baik, berkesinambungan, dan aktif 
sebagai upaya untuk memetakan kompetensi dan kinerja tenaga pengajar.

JW Juga menyatakan bahwa: kepala sekolah telah menjalankan visi dan misi sekolah secara aktif, berkesinambungan, baik, dan terarah dalam mengelola sekolah, memimpin sekolah, membina tenaga pengajar, memantau pelaksanaan pembelajaran dan kinerja tenaga pengajar, pengambilan keputusan, dan pemberdayaan kinerja tenaga pengajar.

LKY Menyatakan bahwa: kepala sekolah telah melakukan pemetaan kompetensi dan kinerja tenaga pengajar sebagai dasar penentuan kebijakan untuk meningkatkan kualitas tenaga pengajar.

MW Juga menyatakan bahwa: kepala sekolah telah menjalankan perannya sebagai supervisor secara berkesinambungan, aktif, dan memberikan inovasi dalam melakukan supervisi administrasi, supervisi akademik, dan supervisi klinis.

MF Mangatakan bahwa: kepala sekolah sudah menjalankan perannya sebagai supervisor secara berkala, berkesinambungan, aktif, dan memotivasi tenaga pengajar jika ada perbaikan dari kesalahan yang telah diperbuat oleh tenaga pengajar.

ND Juga mengatakan bahwa: kepala sekolah sudah menjalankan perannya sebagai supervisor dengan sangat baik melalui kegiatan supervisi administrasi, supervisi akademik, dan supervisi klinis, serta memberikan tindak lanjut pembinaan jika ditemukan hal-hal yang kurang berjalan sebagaimana mestinya.

NL Mengatakan bahwa: kepala sekolah akan memberikan hadiah (reward) dalam bentuk verbal, yaitu sanjungan jika tenaga pengajar aktif dan menunjukkan prestasi atau kinerja yang baik atau sebaliknya.

NW Juga mengatakan bahwa: bahwa kepala sekolah telah melaksanakan supervisi adminstrasi, supervisi akademik, dan supervisi klinis sebagai upaya untuk menjalankan perannya sebagai supervisor.

RD Mengatakan bahwa: kepala sekolah telah bermusyawarah dan mengadakan rapat untuk melibatkan tenaga pengajar dalam merumuskan visi dan misi sekolah, program dan kegiatan sekolah, serta kepanitiaan atau kegiatan lainnya.

SB Juga mengatakan bahwa: kepala sekolah telah melibatkan tenaga pengajar dalam merumuskan visi dan misi sekolah, program dan kegiatan sekolah, serta kepanitiaan atau kegiatan lainnya.

SA Mengatakan bahwa: kepala sekolah memantau dengan sangat baik pelaksanaan pembelajaran dan kinerja tenaga pengajar di kelas.

SK Juga mengatakan bahwa: Kepala sekolah telah menjalankan visi dan misi sekolah dengan sangat baik dalam mengelola dan memimpin sekolah, serta dalam membina tenaga pengajar.

ST Mengatakan bahwa: kepala sekolah telah memberdayakan kinerja tenaga pengajar melalui pembinaan dengan cara memberikan motivasi.

SL Juga mengatakan bahwa: kepala sekolah telah melaksanakan perannya sebagai supervisor dengan melakukan supervisi adaministrasi, supervisi akademik, dan supervisi klinis. Kepala sekolah telah melaksanakan supervisi ini dengan baik, berkesinambungan, dan selalu aktif. Hasil pelaksanaan supervisi menjadi acuan untuk melakukan tindak lanjut pembinaannya.

SMS Mengatakan bahwa: kepala sekolah telah mengadakan rapat dan bermusyawarah bersama melibatkan tenaga pengajar dalam merumuskan visi dan misi sekolah, program dan kegiatan sekolah, serta kepanitiaan atau kegiatan lainnya.

Kendala-kendala apa sajakah yang dihadapi kepala sekolah dalam meningkatkan kinerja tanaga guru SDN Lakkang dan SMPN 44 Makassar dapat dilihat pada tabel berikut:

Tabel 5

Kendalan peran kepala sekolah dalam meningkatkan kinerja tenaga guru

\begin{tabular}{cl}
\hline Idensial & \multicolumn{1}{c}{ Hasil } \\
\hline K.P & Mengatakan bahwa: untuk peran manajerial, supervisor, dan motivator kepala sekolah \\
& mengalami kendala, adanya tenaga pengajar yang tidak melaksanakan tugas yang diberikan. Hal \\
& ini menunjukkan bahwa tenaga pengajar belum memiliki kesadaran akan tugas dan tanggung \\
& jawab, padahal kepala sekolah sudah membagi tugas dan tanggung jawab secara bersama-sama \\
& melalui rapat pembagian tugas.
\end{tabular}


K.P Juga mengatakan bahwa: dalam menjalankan peran dan tugasnya sebagai menejerial, supervisor, motivator adalah persoalan waktu yang tidak terjadwal dengan baik. Artinya, terkadang untuk melaksanakan supervise itu gagal dilaksanakan karena tidak ketemu waktunya antara tenaga pengajar dan kepala sekolah, sehingga saran ke depan perlu diatur jadwal dengan baik.

Peran kepala sekolah dalam meningkatkan kinerja tenaga guru SDN Lakkang dan SMPN 44 Makassar

Dalam rangka meningkatkan kinerja guru di SDN Lakkang dan SMPN 44 Makassar, seorang kepala sekolah harus mampu mengelola sumber daya sekolah secara efektif guna merencanakan dan mengevaluasi visi dan misi sekolah, program dan kegiatan sekolah, pengembangan kurikulum, proses pembelajaran, pengelola staf, fasilitas dan sumber belajar, keuangan, layanan siswa, hubungan sekolah dengan masyarakat, serta menciptakan lingkungan belajar yang sehat dan nyaman. Akibatnya, kepala sekolah harus memiliki pengetahuan pribadi, staf pengajar, keterampilan visual dan misi, serta program dan kegiatan sekolah sebagai pemimpin. Hal ini sejalan dengan (Riski \& Gistituati, 2021) mengatakan bahwa peran kepala sekolah dijalankan dengan baik dalam meningkatkan kinerja guru, kepala sekolah harus mendukung semua kegiatan yang dilakukan guru dalam mencapai kompetensi yang dimilikinya, agar guru dapat menerapkan kompetensi tersebut kepada siswanya.

Menurut (Matondang, 2021) juga mengatakan bahwa kepalah sekolah sudah melaksanakan tugas dan tanggungjawabnya dengan baik, seorang kepala sekolah harus mampu memberikan strategi kepada tenaga guru supaya lebih berkualitas kinerjanya. (Lalu Fauzi Haryadi, 2021) mengatakan bahwa kepala sekolah harus mampu mengatasi berbagai pelanggaran guru, dan sebagai pelajaran, kepala sekolah harus memberikan motivasi terkait kedisiplinan seorang guru. Karena disiplin merupakan faktor terpenting dalam meningkatkan kinerja guru.

\section{Kendala-kendala kepala sekolah dalam meningkatkan kinerja tenaga guru SDN Lakkang dan SMPN 44 Makassar}

Mengenai peran kepala sekolah dalam meningkatkan kinerja guru di SDN Lakkang dan SMPN 44 Makassar, permasalahannya adalah meskipun kepala sekolah telah membagi tugas dan tanggung jawab melalui rapat pembagian, masih ada guru yang belum memiliki kesadaran yang tinggi akan tugas dan tanggung jawabnya. tanggung jawab. Sebagai supervisor, masalahnya adalah koordinasi waktu antara staf pengajar dan kepala sekolah, sedangkan sebagai motivator, tantangannya adalah guru terkadang tidak mengetahui profesi guru. Untuk menghindari hambatan tersebut, kepala sekolah harus memberikan bimbingan khusus dengan mengajak dirinya dan siswanya untuk berpartisipasi dalam berbagai kegiatan ilmiah. Menurut (Ilmin Sakir, 2018) mengatakan bahwa diperlukan kerjasama yang baik antara kepala sekolah dan guru dalam rangka meningkatkan kinerja guru. Semua kegiatan yang mendukung peningkatan kinerja guru akan diwujudkan secara bersama-sama melalui kerjasama yang akan menghindari kendala yang dihadapi kepala sekolah.

Menurut (Harun \& Nurlisa, 2021) juga mengatakan bahwa Seorang kepala sekolah harus mengembangkan kompetensi guru agar kiprahnya berkualitas dan berdaya saing di era globalisasi, serta guru dapat memberikan yang terbaik bagi siswanya.

\section{KESIMPULAN}

Dari hasil penelitian dan pembahasan dapat disimpulkan bahwa 1) peran kepala sekolah sebagai manajerial, supervisor, dan motivator dalam meningkatkan kinerja guru. Inilah peran utama kepala sekolah dalam meningkatkan kualitas guru di SDN Lakkang dan SMPN 44 Makassar. 2) Peran kepala sekolah dalam meningkatkan kinerja guru; terdapat kendala yang dihadapi kepala sekolah, seperti sulitnya mengatur waktu antara kepala sekolah dengan guru, kurangnya kesadaran guru akan kompetensinya, dan guru yang tidak menyelesaikan tugas yang diberikan. 
571 Peran Kepala Sekolah dalam Meningkatkan Kinerja Tenaga Guru Sekolah Dasar dan Sekolah Menegah Pertama - Nuriati, Muhammad Azis, Husain AS

DOI: https://doi.org/10.31004/edukatif.v4i1.1835

\section{UCAPAN TERIMA KASIH}

Ucapan terima kasih kepada Prof. Dr. H. Muhammad Azis, M.Si dan Dr. Husain AS, M.Pd, selaku pembimbing yang telah memberikan arahan dalam penyusunan tesis ini, terima kasih kepada pihak sekolah SD Negeri Lakkang dan SMP Negeri 44 Makassar yang telah memberikan izin kepada penliti.

\section{DAFTAR PUSTAKA}

Aprilianti, J. A. H. dan A. L. (2019). Meningkatkan Kualitas Guru dengan Mengulas Karya Sastra Literatur (Literasi ) Setiap Apel Pagi di SMK. Buletin Pengembangan Perangkat Pembelajaran, 1(2), 2-5.

Aqib, Z. (2015). Peningkatan Kinerja Guru Melalui Supervisi Edukatif Kolaboratif Secara Periodik di SMK Muhamadiyah 1 Berbek Nganjuk Tahun (Issue 2).

Ayenita Roringi1, Z. (2021). Upaya Kepala Sekolah dalam Meningkatkan Mutu Pendidikan di SD Inpres 2 Birobuli. Elementary School of Education E-Journal, 9(2), 147-154.

Ayok, M. (2021). Pentingnya Kualitas Guru dan Keterlibatan Orang tua dalam Meningkatkan Kualitas Siswa. Logon Zoes: Jurnal Teologi, Sosial Dan Budaya, 4(1), 77-88. https://doi.org/10.53827/lz.v4i1.27

Harun, A., \& Nurlisa, S. T. (2021). Kepemimpinan Kepala Sekolah dalam Mengembangkan Kualitas Tenaga Pendidik di RA Principal Leadership in Developing the Quality of Educators in RA. Jurnal Ilmiah Pendidikan Anak Usia Dini, 4(2), 187-197.

Ilmin Sakir, S. H. (2018). Peran Kepala Sekolah Sebagai Manajer (Studi Multisitus) di MIN 1 dan MIN 2 Flores Timur. Jurnal Kebijakan Dan Pengembangan Pendidikan, 6(2), 197-208.

Lalu Fauzi Haryadi, S. (2021). Peran Kepala Sekolah dalam Meningkatkan Kedisiplinan Guru di SMP Islam Plus Darul Hukumaini Jonggat. Al-Nahdlah: Jurnal Pendidikan Islam, 1, 19-27.

Matondang, L. (2021). Kinerja Kepala Sekolah sebagai Supervisor dalam Meningkatkan Profesionalisme Guru di Sekolah Menengah Pertama. Edukatif: Jurnal Ilmu Pendidikan, 3(6), 4094-4101.

Mihmidaty Ya'cub, D. S. G. (2021). Strategi Kepala Sekolah dalam Meningkatkan Pembelajaran Melalui Pengembangan Sarana Prasarana Kualitas. 2, 60-69.

Muflihah, A. (2019). Peran kepala sekolah dalam meningkatkan manajemen mutu pendidikan di madrasah ibtidaiyah. Journal Quality, 7(2), 48-63.

Muqowim, L. L. Y. L. M. (2021). Peran Kepala Sekolah Terhadap Kebijakan Pendidikan Inklusi di Tingkat Sekolah Dasar. Jurnal Kependidikan, 7(3), 708-718.

Prasetia, M. E. (2021). Peran Kepala Sekolah Sebagai Supervisor Kinerja Guru Bimbingan dan Konseling. Jurnal Bimbingan Dan Konseling Islam, 5(2), 165-174.

Ramdani, Z. (2018). Kolaborasi Antara Kepala Sekolah , Guru , dan Siswa. 1st National Conference on Educational Assessment and Policy (NCEAP, 71-78.

Riski, H., \& Gistituati, N. (2021). Kepemimpinan Kepala Sekolah di Sekolah Menengah Pertama. Edukatif: Jurnal Ilmu Pendidikan, 3(6), 3531-3537.

Sultoni, J., \& Nurabadi, I. A. A. (2019). Kepemimpinan Kepala Sekolah dalam Penguatan Peran MultiStakeholders Forum. Sekolah Dasar: Kajian Teori dan Praktik Pendidikan, 1(5), 1-10.

Tri Yuliani, M. K. (2016). Peran Kepemimpinan Kepala Sekolah dalam Membina Kompetensi Sosial (Pelayanan Prima) Tenaga Administrasi Sekolah. JMKSP, 1(2), 122-132.

Yantoro, A. I. (2020). Pelatihan Peningkatan Kompetensi Guru Dalam Meningkatkan Mutu Pembelajaran Berbasis ICT pada SMP Negeri 1 Muaro Jambi. DEDIKASI: Jurnal Pengabdian Masyarakat, 2(2), 311-327.

Yeni Wulandari, Eva Dwi Sartika, \& P. (2018). Strategi Kepala Sekolah Perempuan dalam Meningkatkan Mutu Pendidikan. Jurnal Manajemen, Kepemimpinan, Dan Supervisi Pendidikan, 3(1), 126-136. 